\title{
Research of Market Maturity Phases of Energy Technologies
}

\author{
Azat Rafailovich Sadriev, Bulat Nailevich Kamaev
}

\begin{abstract}
The article discusses the patterns in the market positioning of various energy technologies and identifies technological developments that are residing in the early stages of the market maturity cycle. The study is based on the use of the Hype Cycle conceptual platform and methods of cluster and classification analysis, the functionality of which is implemented using the Mclust software package from the realm of the programming language $R$. The information on patent and publication activity presented in global search engines Google Patents and Google Scholar has served as the informational basis for the analytical procedures conducted. The main provisions of the study were tested on the example of transformers for a voltage of $220 \mathrm{kV}$. For this technological development, its critical structural elements are identified, including heat exchangers with forced circulation of oil (air), oil-air coolers, on-load tap-changers, bushings with the main insulation of the porcelain tire, and bushings with gas insulation, each of which is analyzed from the point of view of existing patterns of its positioning on the Hype Cycle. It has been established that most of these structural elements are within the framework of the "slope of enlightenment" and "plateau of productivity" phases, which characterizes the energy technology under study as already established one, which, in combination of its characteristics, goes beyond the developments of an innovative profile.
\end{abstract}

Keywords : energy technologies, market positioning, Hype Cycle, patent and publication activity, cluster-classification analysis.

\section{INTRODUCTION}

Differentiation of technological development directions significantly enhances the influence of the uncertainty factor on choosing innovative activity priorities of economic systems. The current situation is aggravated by the tendency of a shortened life cycle of innovative developments created in many areas of economic activity [1-2]. In this regard, it is of particular interest to choose such innovation development priorities, following which could have ensured the creation of innovations with high market novelty, substantial and solvent market demand, as well as the time stability of their main competitive advantages [3-4]. To date, a large number of methodological approaches have been developed in the world science designed to solve this problem. Basically, most of these approaches are focused either on the use of expert assessments, including questioning and interviewing in various professional communities, or on the implementation of statistical analysis tools, the most popular of which are

Revised Manuscript Received on October 15, 2019.

* Correspondence Author

Azat Rafailovich Sadriev, Kazan Federal University

Bulat Nailevich Kamaev, Kazan Federal University extrapolation, probabilistic, regression and correlation analysis.

The main sources of information for conducting statistical research are the data on patent and publication activity, which are one of the first formally recorded indicators of the emergence of innovation [5]. Of course, a certain and sometimes quite significant part of innovative developments in certain fields of activity is not amenable to early detection with the help of patent and scientific data [6] largely due to the protection of information about these developments in the commercial secret mode. This to a certain extent reduces the objectivity of the results of scientific research in the field of priority areas of innovative development, however, not to the extent that could affect the transition to the use of alternative data from other sources of information [7].

A typical example of developments devoted to the analysis of promising areas of innovation using patent databases are the studies [8-11] conducted by the scientific team with the participation of K. Miyazaki, J. Tiecheng, K. Nishida, S.K. Chan, Y. Inoue and K. Kato. The peculiarity of their approach is to conduct an international patent search that identifies promising technologies in the early stages of development and predicts their potential impact on changing the quality of services or products in various fields of activity. A similar goal when performing a patent analysis was set by the authors of the paper [12]. Using an example of a study of patent data on the scope of activities for the development of food additives, they reveal possible directions for using the information obtained for a targeted search for partners necessary for the joint implementation of specialized innovative projects. From the position of the formation of innovative networks in the field of nanotechnology and the choice of the direction of their development and the features of patent analysis, a comparable approach is considered in the paper [13].

The scientific work [14] is oriented to the study of technological development trends in the field of automotive software. As a main tool for its implementation, the original algorithm of patent search queries was used, covering not only the names of the relevant documents of protection, but also the summaries and claims contained therein. A similar approach, implemented, however, in relation to the field of activity on the creation of pacemakers, was proposed in the study [15]. The system of special indicators that allow you extracting data from a patent application for a comprehensive analysis of the entire array of patent applications in a specific subject area is of particular interest in this study. The results obtained in this case make it possible to fairly simply evaluate the current phase of the life cycle of the analyzed object and justify the feasibility of further 


\section{Research of Market Maturity Phases of Energy Technologies}

investment in its development. In relation to the sphere of activity on the creation of LED technologies, the same approach is revealed in the study [16], and in relation to technologies in the field of defense and aerospace industry is deliberated in the article [17].

From the point of view of choosing areas of innovation at the level of individual companies, patent analysis is considered in the article [18]. The main idea of the authors of the study, conducted on the example of 21 engineering enterprises from Europe and Japan, is to analyze two types of patent portfolios: their own corporate portfolio, the data for which are used to compare with data on similar portfolios of competing companies, as well as a portfolio including entire set of patents in a specific technological field.

The consideration of the prospects for the development of individual technologies in the article [19] is somewhat different. Being based on four main sources of information, including data on the current life cycle of a particular technology, data on its diffusion rate, data on the extent of patent protection, as well as data on the potential for expanding demand for this technology, the authors propose making recommendations for investors, residing on the stage of choosing an investment object. Three technologies were chosen to test the approach developed in the article: thin-film transistor-liquid crystal displays, flash memory systems and personal digital assistants.

The article [20], in which the analysis of patent information is used to identify the type of innovation created in the period of the years 1963-2009 in the field of solar and wind energy, is of no less interest for the purposes of the study. The main types of such innovations were identified as mass innovations that are not distinguished by significant technological effectiveness, and high-tech innovations, which, on the contrary, are characterized by a relatively high level of complexity. The article [21] presents the results of another development devoted to the analysis of the prospects for the development of technologies in the energy sector. The authors of the article formulated and tried solving the problem of studying the gap between innovative processes in the field of traditional fuel energy and in the field of renewable energy sources.

Thus, a review on existing approaches to the market positioning of various technological developments and the possibilities of using them to select promising areas of technological development allows us drawing the following conclusions:

first, the problem of choosing the directions of innovative development of economic systems is widely discussed in the scientific community. One of the most popular tools used in conducting relevant research is the analysis of patent information. The results of such an analysis make it possible to assess the prevailing trends in the development of individual technologies and to predict their further market positioning. Much attention is paid to the elaboration of forecasts for the development of various technologies using data on search queries in global information networks, information on the demand for products of a particular purpose, information on the number of scientific publications in different subject areas, etc. At the same time, a combination of several information sources is rarely used in the studies being conducted, which reduces the objectivity of the results obtained in this case;

second, a distinctive feature of existing studies is the use of traditional statistical analysis tools, including, first of all, expert and correlation-regression analysis methods. Meanwhile, with all the advantages of these methods, they are significantly inferior in their functional capabilities to machine learning methods, among which the methods of cluster and classification analysis should be especially noted.

All these issues indicate that in the methodological support of research conducted to identify promising areas of technological development, there are still some unresolved problems existing, determining the feasibility of further research in this area.

\section{METHODS}

While carrying out the study, the Hype Cycle conceptual platform was being used, being adapted to identify the patterns in the dynamics of market positioning of energy technologies for various purposes. The choice of the Hype Cycle concept during the study is determined by the following circumstances. Firstly, by the limitations of the traditional concept of the product life cycle associated with its inability to fully disclose the features of the market positioning of various types of products, including innovative developments. In this regard, Hype Cycle, which operates with the more informative phases of positioning, each of which is characterized by a different degree of interest from society and professional specialists, seems to be more suitable for implementation in the innovative field of activity. Secondly, by the ability to use a sufficient number of quantitative and qualitative indicators in the study of the phases of market positioning of innovations, including, for example, the number of participants in the core market and the share of products under consideration, the number of registered patent applications, patents and scientific publications in the corresponding subject area, target indicators of search queries from the Google trends database, etc. Third, the open nature of Hype Cycle allows one to flexibly approach the study of a whole complex of different generations of the technologies or types of products being analyzed, combining several trajectories of the life cycle on the same graphic field.

It should be noted that the Hype Cycle concept considers market recognition of innovation using five main phases [22]:

"technology trigger" phase, which refers to the appearance of the first information about innovation on the market;

"peak of inflated expectation" phase, when revolutionary properties are expected from the new technology, and thanks to its novelty, it is gaining popularity and is becoming the subject of wide discussion in the relevant market environment;

"trough of disillusionment" phase, which is characterized by the identification of certain shortcomings in the innovative technology, as well as a decrease in the level of market novelty, which cumulatively contribute to a certain decrease in interest from the target audience

"slope of enlightenment" phase, when the technology eliminates previously 
identified deficiencies, whereby there is a gradual restoration of previously decreased interest in it and an increase in the volume of corresponding sales is also observed;

"plateau of productivity" phase, at which the maturity of technology sets in and society begins to perceive the corresponding development as already quite traditional one, being objectively aware of all its advantages and disadvantages.

The accomplishment of calculations, which made it possible to carry out a quantitative substantiation of the features of the passage of the technological developments under consideration through the different phases of the Hype Cycle, were based on the implementation of a set of cluster-classification analysis methods [23], including the EM algorithm, k-means, Ward.D, Gap Statistics, Sillhuet, as well as Bayesian Information Criterion, Hubert Index and D-Index. To do this, we used the functionality of the software package "Mclust", designed to process statistical data in the realm of the programming language $\mathrm{R}$.

The research was based on the data of the Google Patents and Google Scholar search engines on the dynamics of patent and publication activity in the field of development of transformers for $220 \mathrm{kV}$ voltage. The data used in the calculations cover the time period of the years 1930-2017, including several thousand units of the initial statistical material. As an indicator of patent activity, global data on the number of registered patent applications for inventions corresponding to the profile of the analyzed subject area were used. Publication activity was studied using the number of published and indexed scientific publications, the names and keywords of which characterize them as corresponding to the subject area under consideration.

\section{RESULTS AND DISCUSSION}

At the initial stage of the analytical procedures, a structural analysis of the transformer research of the object under study for a voltage of $220 \mathrm{kV}$ was performed and its basic structural elements were determined. Each of them was considered from the point of view of the contribution to the achievement of the main technical result from the use of transformers for

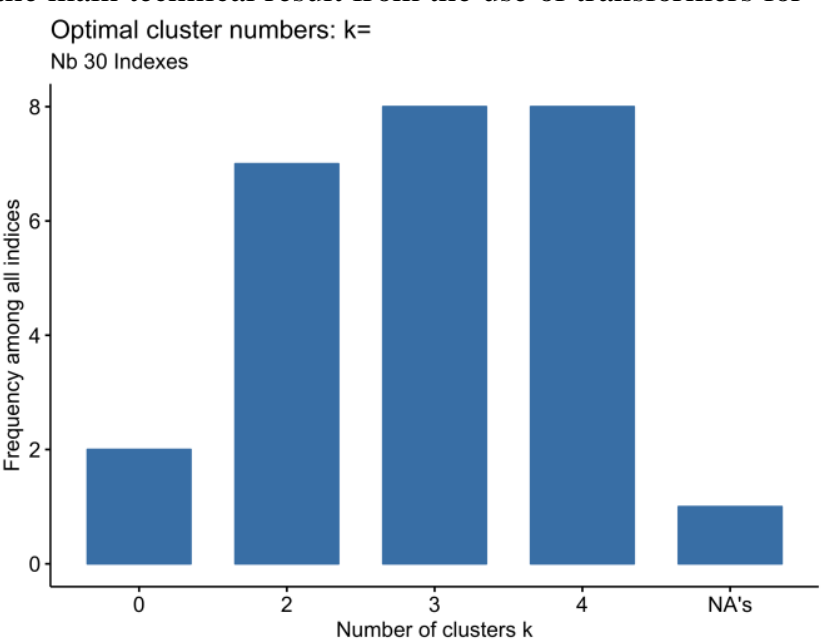

providing galvanic isolation of high voltage circuits from the low voltage of the secondary windings. It was found that the design of the transformers includes over twenty different structural elements, the most important of which are heat exchangers with forced circulation of oil (air), oil-air coolers, on-load tap-changers, bushings with the main insulation of the porcelain tire, as well as gas-insulated bushings.

For each of these five structural elements, a cluster analysis of data on patent and publication activity in the specialized fields of science and technology was carried out, starting from the date of the first documentary references to the corresponding generation of the analyzed research object. In the case of heat exchangers with forced circulation of air (oil), the depth of the corresponding data array dates back to the year 1980 (Figure 1).

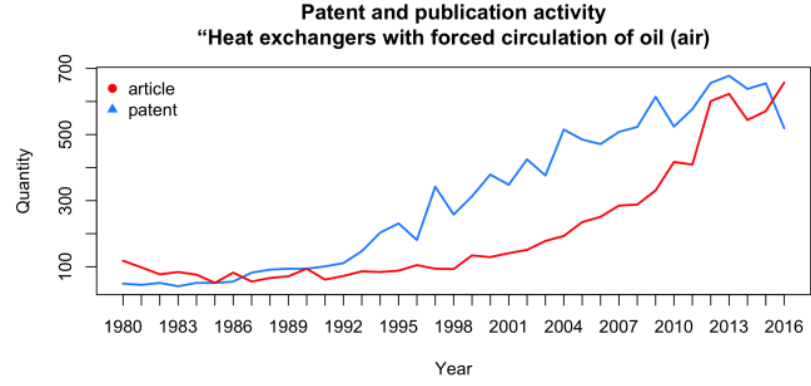

Figure 1. Dynamics of patent and publication activity within the subject area "Heat exchangers with forced circulation of oil (air)" *

* compiled according to Google Patents and Google Scholar The presented array of information was structured, and using the NbClust and Mclust packages, was determined the number of clusters and proposed the best clustering scheme from the different results obtained by varying all combinations of number of clusters, distance measures, and clustering methods. An analysis of the results of the calculations performed in this case, presented in Figure 2, indicates that the optimal number of clusters for the data array under consideration, is 4 units.

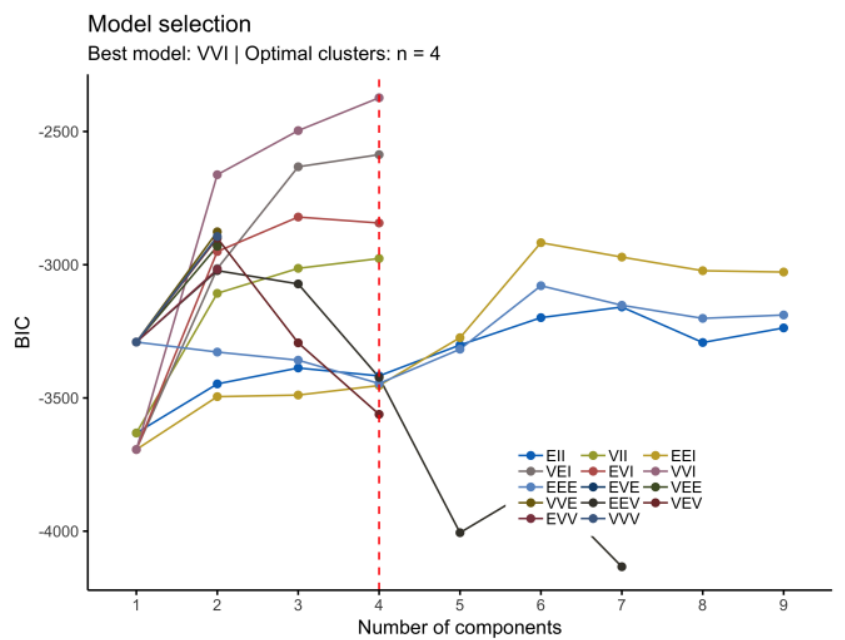

Figure 2. The results of calculating the optimal number of clusters for patent and publication applications in the field of "Heat exchangers with forced circulation of oil (air)" made between 1980 and 2016 years using 30 indices methods and Gaussian finite mixture models fitted via EM algorithm for model-based clustering 


\section{Research of Market Maturity Phases of Energy Technologies}

A graphical interpretation of the resulting distribution of data across clusters is shown in Figure 3. The captured scatter plot reveals the nature of clustering of main data groups: a group of data on the number of registered patents, a group of data on the number of published. Scales located along the contour of the outer boundaries of the matrix show the distance of cluster elements from their centroids, the

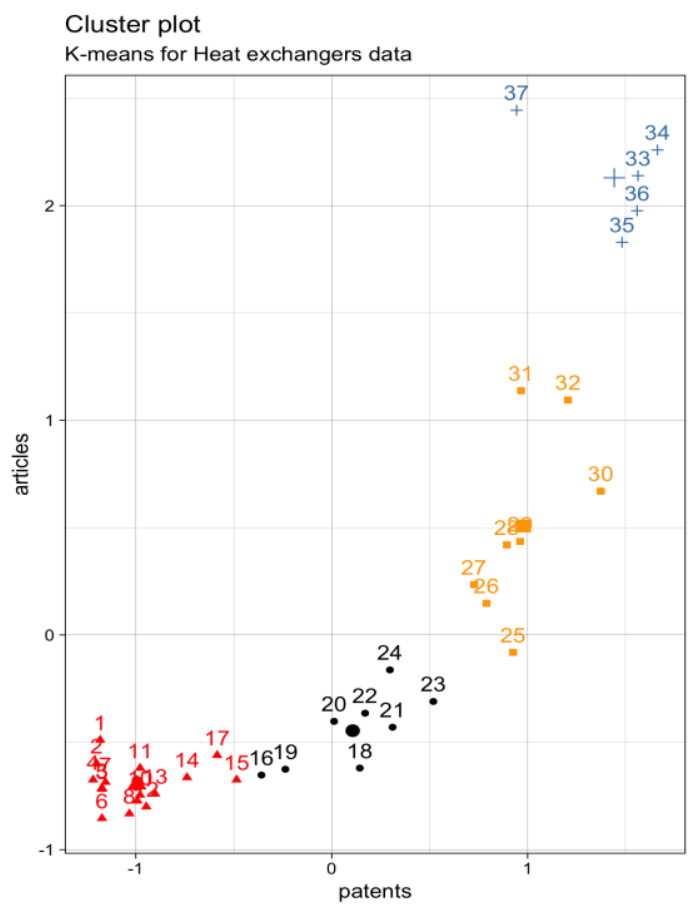

position of which is fixed at zero. Analysis of the information presented in the figure indicates a relatively high concentration of elements of the first, second, and fourth clusters and, conversely, a more diffuse structure of the third data cluster.

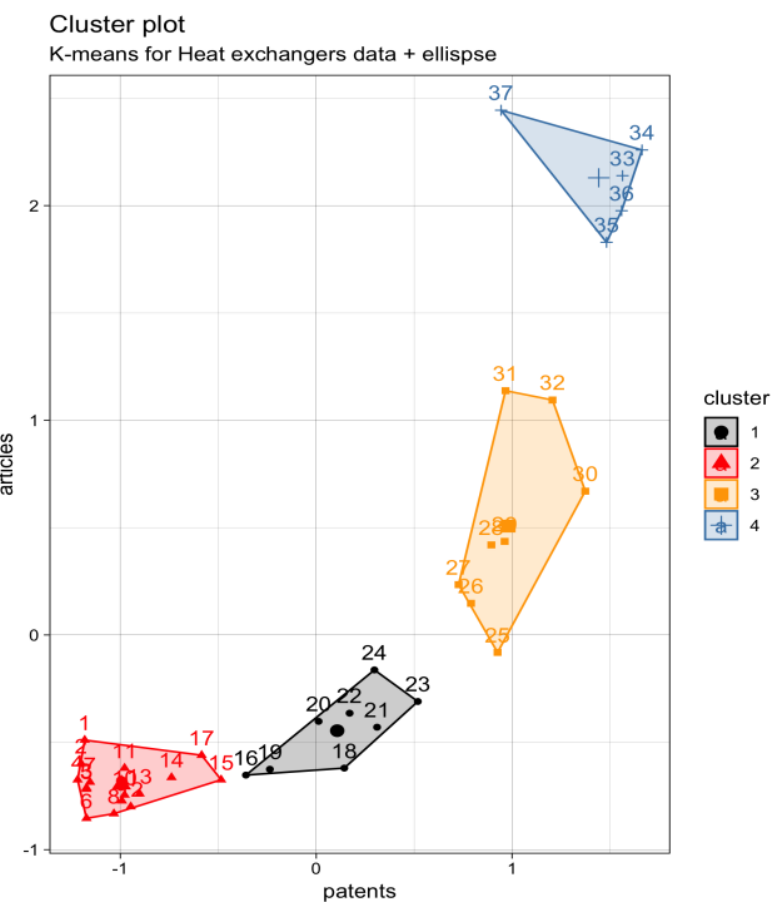

Figure 3. Clustered scatter plot diagram for the number of patents and scientific publications in the field of heat exchangers with forced circulation of oil (air)

In order to visualize the presentation of the shapes and sizes of the identified clusters, a two-dimensional scattering diagram was constructed, in which the positions of the analyzed data were determined using the principal component method (PCA) (Figure 4). The placement of data points on the diagram was made depending on the type of correlation observed between them - positive, the region of which is represented on the upper right and lower right Standard deviation : patens $=0.38914 ;$ articles $=1.3596$ Varience :

patens $=0.07571628 ;$ articles $=0.9242837$

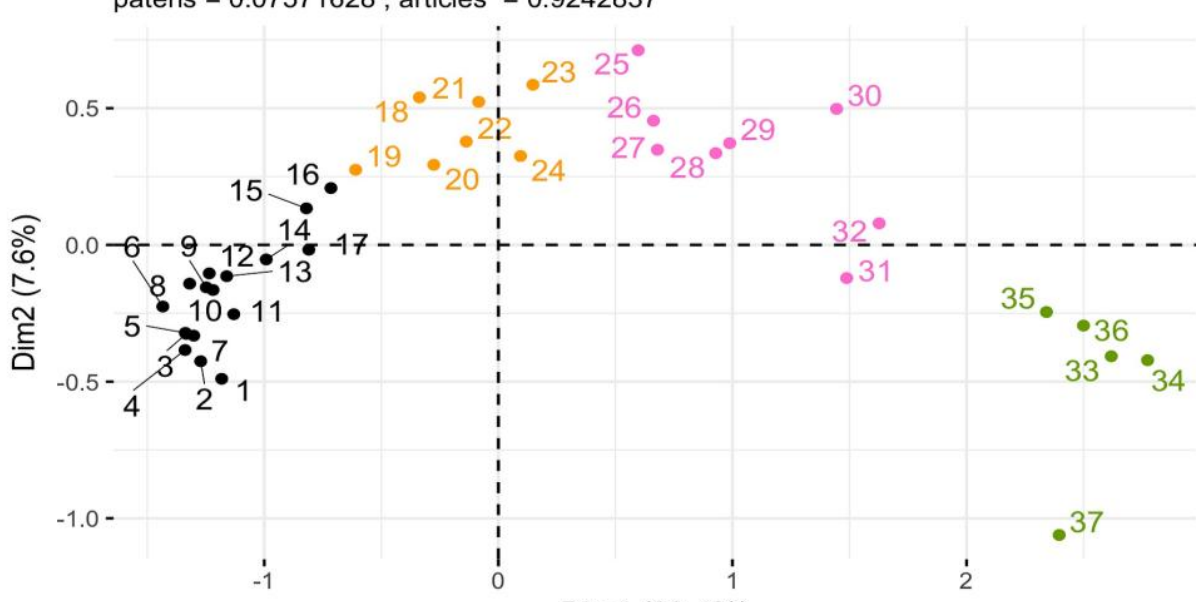

$\operatorname{Dim} 1(92.4 \%)$

Figure 4. PCA Scatterplot diagram showing the distribution of the publication and patent data across clusters for heat exchangers with forced circulation of oil (air)

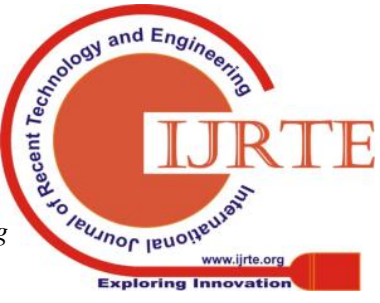


In the case of heat exchangers with forced circulation of oil (air), the results of this binding are systematized in table 1.

Table 1. Periods of the onset of various phases in the structure of "Hype Cycle" for technology of heat exchangers with forced circulation of oil (air)

\begin{tabular}{|l|c|c|}
\hline $\begin{array}{c}\text { Name of «Hype } \\
\text { Cycle» phase }\end{array}$ & $\begin{array}{c}\text { Year of phase } \\
\text { beginning }\end{array}$ & $\begin{array}{c}\text { Year of phase } \\
\text { ending }\end{array}$ \\
\hline Technology Trigger & 1980 & 1995 \\
\hline $\begin{array}{l}\text { Peak of inflated } \\
\text { expectations }\end{array}$ & 1996 & 2004 \\
\hline $\begin{array}{l}\text { Through of } \\
\text { disillusionment }\end{array}$ & 2005 & 2011 \\
\hline $\begin{array}{l}\text { Slope of } \\
\text { enligthment }\end{array}$ & 2012 & - \\
\hline Platoeu of & - & - \\
\hline
\end{tabular}

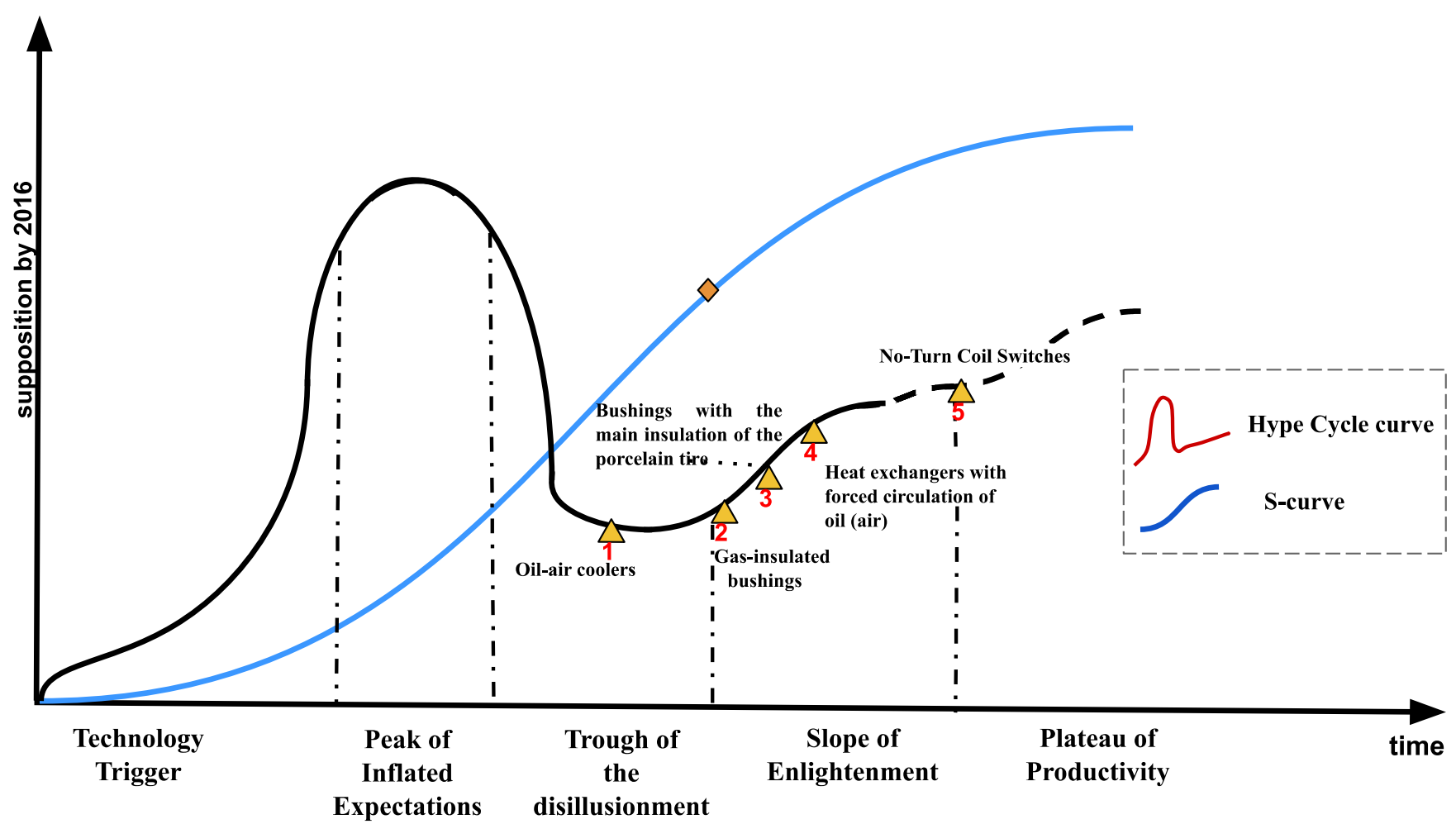

Figure 5. Positioning of the main structural elements that make up the transformers for $220 \mathrm{kV}$ voltage on the Hype Cycle

\section{SUMMARY}

Interpretation of the results of the studies allows arriving to the following conclusions. First, the expansion of the technological development space of economic systems, having a positive impact on the activation of innovative processes, creates difficulties in setting goals in the innovation management system. One of the solutions to this problem is to study the phases of the life cycle of types of products whose production is in the circuit of the analyzed priorities of innovative development. Insufficient completeness and reliability of data revealing the dynamics of market sales of the analyzed types of innovative products limit the possibilities of studying their life cycle. The solution to this problem can be the implementation of analytical procedures using indirect indicators, including, first of all, patents and indexed scientific publications.

\begin{tabular}{|l|c|c|}
\hline $\begin{array}{c}\text { Name of } \begin{array}{l}\text { Hype } \\
\text { Cycle» phase }\end{array} \\
\text { productivity }\end{array}$ & $\begin{array}{c}\text { Year of phase } \\
\text { beginning }\end{array}$ & $\begin{array}{c}\text { Year of phase } \\
\text { ending }\end{array}$ \\
\hline
\end{tabular}

In full accordance with the logic of the cluster data analysis carried out in relation to the field of activity on the creation of heat exchangers with forced circulation of oil (air), a similar study was carried out with respect to the remaining critical structural elements necessary for the production of transformers for $220 \mathrm{kV}$ voltage. They are oil-air coolers, on-load tap-changers, bushings with main insulation of a porcelain tire, and gas-insulated bushings. Omitting a detailed description of the intermediate results, we present the final results of the cluster analysis for each of these elements (Figure 5). 


\section{Research of Market Maturity Phases of Energy Technologies}

\section{CONCLUSION}

The application of the results of the study can be considered from two main points of view. On the one hand, the data obtained form the basis for ranking various types of power equipment by the degree of their innovative potential. This opens up the possibility of identifying development priorities with a high level of innovation, as well as excluding the areas of activity that will not be in demand by the market in the long term from further consideration.

On the other hand, the priority areas of technological development identified owing to the use of patent data and indexed scientific publications are valuable as a source of information about leading developers in the relevant fields of science and technology. Possessing this information allows us to search for world best practices for creating products for a specific purpose, including developments in narrow subject areas that are not adequately reflected in relevant industry reviews.

\section{ACKNOWLEDGEMENTS}

This work was funded by the subsidy, allocated to Kazan Federal University, for the state assignment in the sphere of scientific activities (project №26.2578.2017/4.6).

\section{REFERENCES}

1. Melnik, A.N., Mustafina, O.N., Sadriev, A.R. 2015. Features of formation of the system of innovative development of the industrial enterprise, International Journal of Applied Engineering Research, 10 (18), pp. 39398-39403.

2. Melnik, A.N., Ermolaev, K.A., Kuzmin, M.S. 2019. Mechanism for adjustment of the companies innovative activity control indicators to their strategic development goals, Global Journal of Flexible Systems Management, 20(3), pp. 189-218.

3. Melnik, A.N., Lukishina, L.V., Sadriev, A.R. 2015. Formation of the system of indicators to assess the impact of energy efficiency on the innovative development of the enterprise, International Journal of Applied Engineering Research, 10(20), pp. 40991-40997.

4. Sadriev, A.R., Gabdullin, N.M., Kamaev, B.N. 2018. Impact of innovative processes on Russia's economic growth under sanctions, The Journal of Social Sciences Research, 5, pp. 415-420.

5. Pavitt, K. 1985. Patent statistics as indicators of innovative activities: Possibilities and problems, Scientometrics, 7 (1-2), pp. 77-99.

6. Pavitt, K. 1982. R\&D, patenting and innovative activities. A statistical exploration, Research Policy, 11 (1), pp. 33-51.

7. Dang, J., Motohashi, K. 2015. Patent statistics: A good indicator for innovation in China? Patent subsidy program impacts on patent quality, China Economic Review, 35, pp. 137-155.

8. Yuan, F., Miyazaki, K. 2018. Patents and Networks: Case of discerning the evolutionary nature of technological change in the complex product industry, World Scientific Book Chapters, pp. 93-120.

9. Miyazaki, K., Tiecheng, J., Nishida, K. 2017, July. Co-evolution of technologies, key components and institutions in the case of smart houses in Japan, In 2017 Portland International Conference on Management of Engineering and Technology (PICMET), pp. 1-10.

10. Chan, S. K., Miyazaki, K. 2015, August. Knowledge convergence between cloud computing and big data and analysis of emerging technological opportunities in Malaysia, In 2015 Portland International Conference on Management of Engineering and Technology (PICMET), pp. 1501-1512.

11. Suryanegara, M., Miyazaki, K. 2012. Towards 4g mobile technology: Identifying windows of opportunity for a developing country, International Journal of Technology, 3 (1), pp. 85-92.

12. Fabry, B., Ernst, H., Langholz, J., Köster, M. 2006. Patent portfolio analysis as a useful tool for identifying R\&D and business opportunities-an empirical application in the nutrition and health industry, World Patent Information, 28 (3), pp. 215-225.

13. Guan, J., Liu, N. 2016. Exploitative and exploratory innovations in knowledge network and collaboration network: A patent analysis in the technological field of nano-energy, Research Policy, 45 (1), pp. 97-112.

14. Xie, Z., Miyazaki, K. 2013. Evaluating the effectiveness of keyword search strategy for patent identification, World Patent Information, 35 (1), pp. 20-30.
15. Haupt, R., Kloyer, M., Lange, M. 2007. Patent indicators for the technology life cycle development, Research Policy, 36 (3), pp. 387-398.

16. Lee, C., Kang, B., Shin, J. 2015. Novelty-focused patent mapping for technology opportunity analysis, Technological Forecasting and Social Change, 90 (PB), pp. 355-365.

17. Grimaldi, M., Cricelli, L., di Giovanni, M., Rogo, F. 2015. The patent portfolio value analysis: A new framework to leverage patent information for strategic technology planning, Technological Forecasting and Social Change, 94 (1), pp. 286-302.

18. Ernst, H. 1998. Patent portfolios for strategic R\&D planning, Journal of Engineering and Technology Management - JET-M, 15 (4), pp. 279-308

19. Altuntas, S., Dereli, T., Kusiak, A. 2015. Forecasting technology success based on patent data, Technological Forecasting and Social Change, 96, pp. 202-214.

20. Huenteler, J., Schmidt, T.S., Ossenbrink, J., Hoffmann, V.H. 2016. Technology life-cycles in the energy sector - Technological characteristics and the role of deployment for innovation, Technological Forecasting and Social Change, 104, pp. 102-121.

21. Noailly, J., Smeets, R. 2015. Directing technical change from fossil-fuel to renewable energy innovation: An application using firm-level patent data, Journal of Environmental Economics and Management, 72, pp. 15-37.

22. Fenn, J., Raskino, M. 2008. Mastering the hype cycle: how to choose the right innovation at the right time, Harvard Business Press, 339 p.

23. Hastie, T., Tibshirani, R., Friedman, J. 2009. The elements of statistical learning: data mining, inference and prediction, The Mathematical Intelligencer, 27(2), pp. 83-85. 